\title{
Analysis of the Spatial Structure of Beijing from the point view of Weibo Data
}

Liya Yang ${ }^{1}$ | Carlos Marmolejo Duarte ${ }^{2}$

Received: 2020-02-04 | in its final version: 2020-04-24

Abstract

Beijing as the second largest city in China has a controversial urban structure. Traditional methods usually identify the urban structure of cities by analyzing the employment distribution. This research studies the temporal-spatial structure of Beijing metropolitan area in terms of social media activities. It proposes to utilize Weibo (the Chinese equivalent of Twitter) density to describe the citizens' activities in Beijing in one week and adopt the classic exponential model to identify Weibo subcenters. It detects sub-centers in different time periods and compares them with the actual urban land uses. Moreover, the studied area extends to the "peripheral districts" of Beijing, thus it assesses the developmental situation of the whole Beijing area. The results indicate that the structure of Beijing indeed shows a polycentric structure according to the distribution of potential Weibo sub-centers, though the only clear spatial structure of Weibo distribution is confirmed by the model is the period of the weekend. These Weibo sub-centers of weekend are the airport, commercial areas, tourist attractions, universities, and mixed-activity areas, which have intense flows of human activities. Weibo data is proved to be a useful data source to study the urban structure and urban functional areas.

Keywords: urban structure; subcenter; social media data; LBSN

Citation

Yang, L. \& Marmolejo, C. (2020). Analysis of the Spatial Structure of Beijing from the point view of Weibo Data. ACE: Architecture, City and Environment, 15(43), 9302. DOI: http://dx.doi.org/10.5821/ace.15.43.9302

1 PhD Candidate, Universitat Politècnica de Catalunya, Barcelona's School of Architecture (ETSAB), Centre for Land Policy and Valuations, Barcelona, Spain. (ORCID ID: 0000-0002-0247-2701); 2 Associate Professor, Universitat Politècnica de Catalunya, Barcelona's School of Architecture (ETSAB), Centre for Land Policy and Valuations, Barcelona, Spain. (ORCID ID: 0000-0001-7051-7337, WoS Researcher ID: D-9162-2016, Scopus Author ID: $\underline{\text { 35178192000). Contact e-mail: li.ya.yang@upc.edu }}$ 


\section{Introduction}

The urban structure has long been one of the essential topics in urban geography and planning (Marmolejo-Duarte, et al.2016). Traditional methods mostly utilized official demographic census (Marmolejo-Duarte, et al., 2013) or land-use data to analyse the urban structure. However, these indicators are insufficient to capture the dynamics and complexity of urban systems. They only considered employment and residential activities (De Ureña et al., 2013). However, all the other activities that people carry out outside the workplace or home are frequently ignored (MarmolejoDuarte \& Cerda-Troncoso, 2012).

Nowadays, thanks to the development of geo-technologies, a novel channel that shows the changes and operational mechanisms of urban society is opened. The data generated by the Internet or GPStracking can capture the detailed individual activities within cities. Since 2009, the explosion of social media around the world, such as Twitter and Facebook, prompted academic studies based on social media. Despite the ability of social media could break through the limitation of physical distance to some degree, it retains a strong relationship with physical, cultural, and linguistic boundaries (Stephens et al. 2013). Therefore, social media data is a new data source to study the urban structure. For example, Green (2007) discussed the urban structure in terms of the functional perspective, which is based on social network analysis.

Therefore, this paper tries to detect the temporal-spatial structure of the Beijing metropolitan area via Weibo data. Weibo is one of the most popular social media platforms in China where western social media such as Twitter is not used due to censorship. Weibos' function is similar to Twitter which allows users to exchange news or information. According to its earnings report in 2015, the daily active users of Weibo reached 106 million persons in China mainland. In addition, because of the issue of transparency, it is not easy to get the related data to follow the traditional methods for identifying the sub-centers of Beijing, such as data of localized employment and detailed land-uses. Therefore, using the data of daily activities is a way to overcome such data limitations.

This paper choses Beijing as the study area, because it is a very typical megacity that faces many tough challenges and the reform of urban structure. Beijing was one of the top 10 biggest world cities in 2015. The urban scale has been expanded 12 times in 55 years. The total area of modern Beijing has reached to $16,410.54 \mathrm{~km} 2$, which consists of 16 administrative districts. Such rapid urban expansion brought heavy pollution and terrible traffic congestion to the city. Although the Beijing government stressed the reconstruction of urban structure through building sub-centers, the model of urban expansion still like ripples which diffused from the downtown. Whether such planed subcenters effectively affect the urban structure of Bringing deserves to be explored from a broader perspective as it is analysed in this paper. Moreover, the urbanization of Beijing has aroused attention from researchers and officials since many years ago. However, their investigation mainly focused on the urban area within the six districts in the central region, rather than the whole Beijing area. In addition, a few of them introduced social media data to investigate the urban structure of the city.

Therefore, this study prepares to combine urban contexture with Weibo data to detect the subcenters of Beijing. The studied area extends to "peripheral districts" of Beijing, thus we could evaluate the developmental situation of the whole Beijing area. The part of the literature review summarizes pioneer urban researches that cooperate with the time-geography framework and Weibo data. A brief retrospection on the urban structure of Beijing is offered in the third part. The fourth section introduces the exponential model to identify Weibo sub-centers in terms of different periods of a week. The only clear spatial structure of Weibo distribution is confirmed by the model is the period of the weekend. However, the urban structure of Beijing indeed shows a polycentric structure

\footnotetext{
${ }^{1}$ Source: City metric, http://www.citymetric.com/skylines/where-are-largest-cities-world-1051
} 
according to the distribution of potential Weibo sub-centers, though the high-density clusters of Weibo activities mainly gathered in the northern area of Beijing. Despite its inherent limitations, Weibo data successfully identify sub-centers that are not considered by the traditional methods of identification of urban structure, such as university and recreational places.

\section{Literature review}

\subsection{Time-geography framework and the geo-located data}

The Swedish geographer Torsten Hägerstrand brought up the concept of time-geography in the 1960s which observes the world from a four-dimensional view - two-dimensional matter, space and time. Time-geography considers that human being has temporal and spatial attributes. These two features could be separated and reflect the relationship between individual activities and their surroundings. Hence, the city can be seen as a network of human activities and places. In the early phase, the theory of time geography was mainly applied to empirical studies in small scales, due to the limitation of data collection. For example, the PESASP program led by Bo Lenntorp designed an accessibility model for Karlstad's traffic planning in Sweden (Thrift, 1977). In the 1980s, Allan Pred (1984) began to introduce time geography into the macro-scale of human society, combined with the theory of structuration to explain the relationship between individual activities and social reproduction. In recent years, with the development of technologies, geo-visualization and geo-simulation can be realized in multiple spatial scales, and the precision of tracking location has improved substantially. The applications of time geography have expanded to many fields, such as urban transportation, land use and spatial patterns of specific groups, etc.

In the sphere of urban function study, Yuan et al. (2012) combined POls (place of interests) datasets of Beijing and two 3-month data of GPS-tracking to identify urban regions of different functions. Qi et al. (2011) analyzed the functional regions of Hangzhou based on Taxi GPS data. This latter research identified three types of regions: train stations, recreational districts, and scenic spots. Yang \& Marmolejo-Duarte (2019) extracted the travel traces of Foursquare users to study the functional interrelationship between different urban places.

In the sphere of land use, researchers used mobile positioning data and POIs to classify the vacant housing area of cities in China (Chi, et al., 2015). They identified the vacant housing area based on GPS data which could indicate the patterns of human mobility in a span of 9 months. Liu et al. (2012) explored intra-urban land uses in Shanghai from seven-day taxi trajectory data. They borrowed the ecological concept of "source-sink" to characterize the daily travel patterns. According to the Taxi GPS data, a traffic source area is defined as the one having more pick-ups than drop-offs, in other words, there is a net traffic outflow. A traffic sink area is the inverse. Different land uses were associated with different travel patterns. For example, a source-sink area was defined as an area that was a source area in the morning and a sink area in the evening. Therefore, the residential area tended to be associate with the source-sink area.

In the sphere of land use, researchers used mobile positioning data and POIs to classify the vacant housing area of cities in China (Chi, et al., 2015). They identified the vacant housing area based on GPS data which could indicate the patterns of human mobility in a span of 9 months. Liu et al. (2012) explored intra-urban land uses in Shanghai from seven-day taxi trajectory data. They borrowed the ecological concept of "source-sink" to characterize the daily travel patterns. According to the Taxi GPS data, a traffic source area is defined as the one having more pick-ups than drop-offs, in other words, there is a net traffic outflow. A traffic sink area is the inverse. Different land uses were associated with different travel patterns. For example, a source-sink area was defined as an area that

ACE, 15 (43) CC BY-ND 3.0 ES | UPC Barcelona, Spain |Analysis of the Spatial Structure of Beijing from the point view of 
was a source area in the morning and a sink area in the evening. Therefore, the residential area tended to be associate with the source-sink area.

In the sphere of the spatiotemporal structure of urban space, Marmolejo-Duarte \& Cerda-Troncoso (2020) used the density of people's daily activities using origin/destination travel data to identify the sub-centers in the Metropolitan Region of Barcelona. The Livehoods Project (Cranshaw, et al., 2012) utilized Foursquare data to identify characteristics of residents' activities in different areas of Pittsburgh in the United States. Jiang et al. (2012) studied the urban spatial-temporal structure through an open resource -- "Travel Tracker Survey" conducted by the Chicago Metropolitan Agency for Planning in 2008. They aggregated individuals' activity patterns and proved that the daily routines of citizens could be greatly detected and predicted

\subsection{Previous studies of the Beijing urban structure}

Since the end of the 1990s, the urbanization issues of Beijing city have drawn much attention from researchers. Many studies investigated the Beijing metropolitan area from various perspectives and methods. Besides the traditionally documental study (Ai, et al. 2008), remote sensing and GIS have become the prevalent techniques to analyse the urban structure and land use of Beijing (Wu et al. 2006; Xie et al. 2007; Kuang, 2012). The conclusion of these coincides in suggesting that urban sprawl mainly eroded areas of cropland around Beijing. Another important approach is to utilize census data to investigate the social-spatial structure of the city. Feng and Zhou (2003) utilized the second and the fifth Chinese national census in 1982 and in 2000 to compare the changes of the social-spatial structure of Beijing. Huang et al. (2015) used companies registered data to investigate the potential employment sub-centers in Beijing. Interestingly, the former stated that the social-spatial structure of Beijing already shows some characteristics of the polycentric model, but Huang's study showed that the city was still monocentric.

In recent years, "Big Data" has also involved in studies of Beijing city. Beijing City Lab launched a project-SinoGrid to collect various aspects of city life based on $1 \mathrm{~km} 2$ fishnet. Long et al. (2013) combined remoting images, POls data, and Weibo check-in data to explore the degree of mixed landuse in Beijing. They concluded that land-use mixing is higher in the central areas of the city than the peripherical ones. Microsoft Research utilized taxi data combined with POIs to discover the functional regions in Beijing (Yuan, et al. 2012). After comparing with the actual urban contexture, they concluded that the POIs and mobility patterns could be a powerful tool to identify the land uses of a city. Wang et al. (2016) identified seven types of land use clusters in Beijing using Weibo and POls data. They divided the Beijing area into cells with $0.4 \mathrm{~km} 2$ and cluster these cells using the hourly frequency of Weibo on each cell. Based on the temporal active trend of the cluster, they estimated the type of land use and verified it by mining the contents of these Weibos. In summary, the urban structure of Beijing has been explored by various perspectives and technics. However, these studied primarily focus on the land-uses or urban functions, rather than the urban structure. Therefore, our research aims to investigate the urban structure of Beijing based on Weibo activities for filling the gap.

\section{Brief evolution of the urban structure of Beijing}

Beijing is the second-largest city in China, also the political, cultural and technological innovation center of China. The current Beijing consists of 16 districts and more than 20 million permanent residents. Meanwhile, according to the Beijing City Master Plan 2004, the functional structure of Beijing city consists of the capital core zone, the expanded functional zone, the new developing zone and the ecological conservation zone (Figure 1). 
The capital core zone includes Dongcheng and Xicheng district, which is the national political center. The expanded functional zone undertakes the largest proportion of employment and urban services. The new developing zone is the region for future urban development, as well as the agricultural basement. The ecological conservation zone accounts for 53.3\% of the total area of Beijing, which aims to preserve the water resources and the ecological environment.

The modern urban structure of Beijing basically inherits the structure of the Qing Dynasty - centered on the Forbidden City, organized on the north-south axis. In 1949, at the beginning of the People's Republic of China, Beijing was just a city where had 1.65 million people. In 1953, the Beijing government brought up Key Points of Draft Plan for Reconstructing and Expanding Beijing. Based on the plan, urban expansion followed a monocentric model based on four concentric ring roads and several radial ones. However, the heavy industrial pollution in the late 1970 s urged the government to change the urban plan. In 1983, the Beijing government published the Master Plan of Beijing Urban Construction. Since then, the southern part of Beijing has gradually declined, due to the removal of heavy industrial factories. On the contrary, the northern part of the city, especially Zhongguancun, has been developed rapidly, because several famous universities were located in this area, such as Tsinghua University and Peking University.

Figure 1. The functional zones of Beijing according to the 2004 City Master Plan

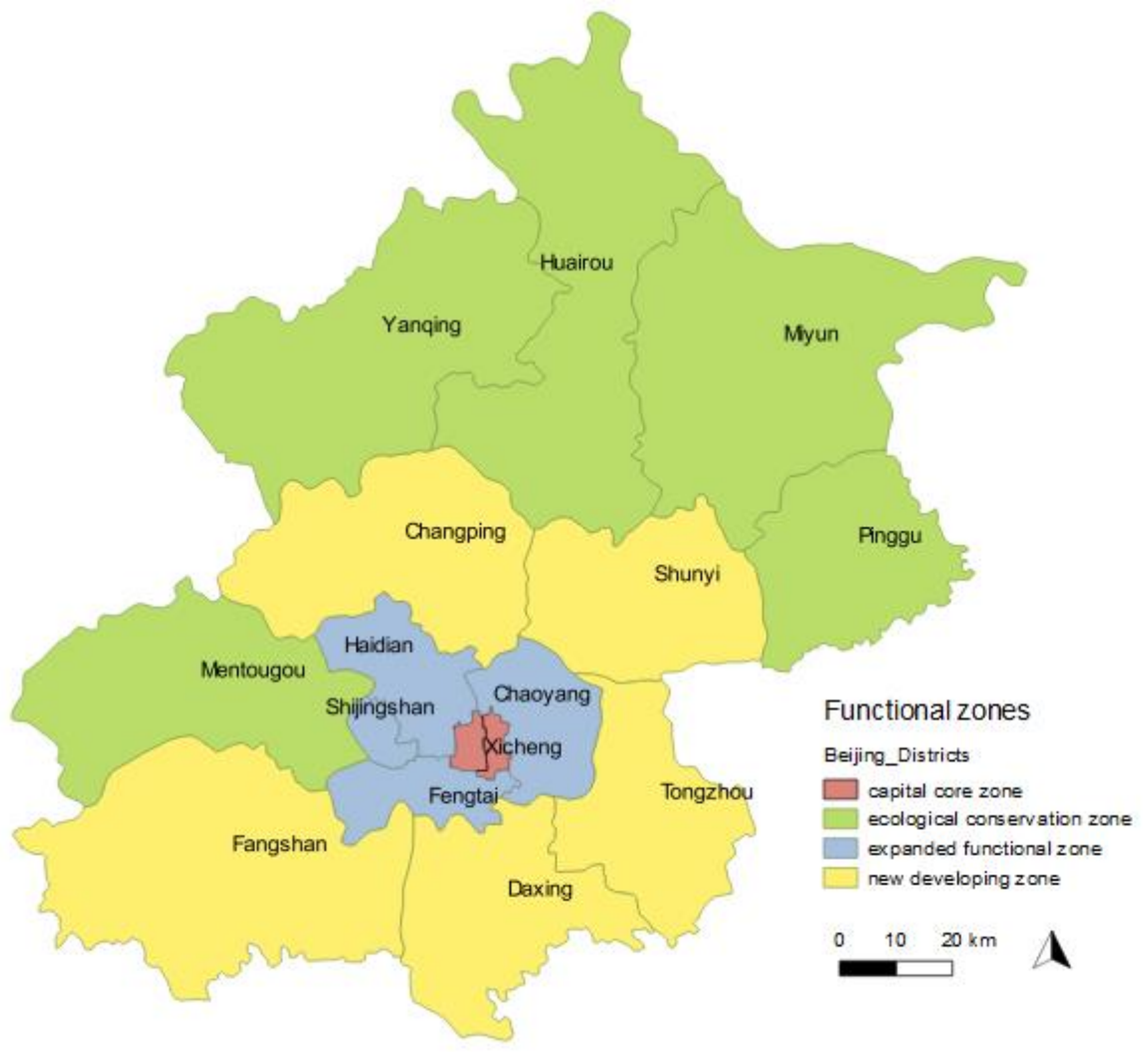

Source: self-elaboration

Ten years later, the Beijing Master Plan (1991-2010) emphasized the importance of controlling the scale of the central city. It planned to reconstruct the urban structure from monocentric mode to "dispersed clusters". Beijing government prepared to build 10 satellite cities to disperse the population. After the new millennium, the model of dispersed clusters indeed helped to disperse the population in the downtown to some degree, whereas the population was soaring in the surrounding areas. The

ACE, 15 (43) CC BY-ND 3.0 ES | UPC Barcelona, Spain |Analysis of the Spatial Structure of Beijing from the point view of

Weibo Data. DOI: http://dx.doi.org/10.5821/ace.15.43.9302 
Beijing government decided to reform the urban structure in 2001. The monocentric model was replaced by a multi-centric development scheme. The layout of Beijing City Master Plan 2004 was "Two Axes - Two Belts - Multi-centers" (Figure 2). "Two axes" refers to the traditional north-south axis and the horizontal line along with Chang'an Street, which aims to protect the traditional spatial structure and its cultural values. "Two-belts" divides Beijing city into an eastern development belt and western environmental belt. "Multi-centers" plans to build several functional centers that could adapt to the requirements of globalization, for example, Zhongguancun Science Park, GuoMao CBD, Olympic center, etc. It planned to build 11 new cities to disperse the population.

Figure 2. The layout of Beijing Master Plan 2004

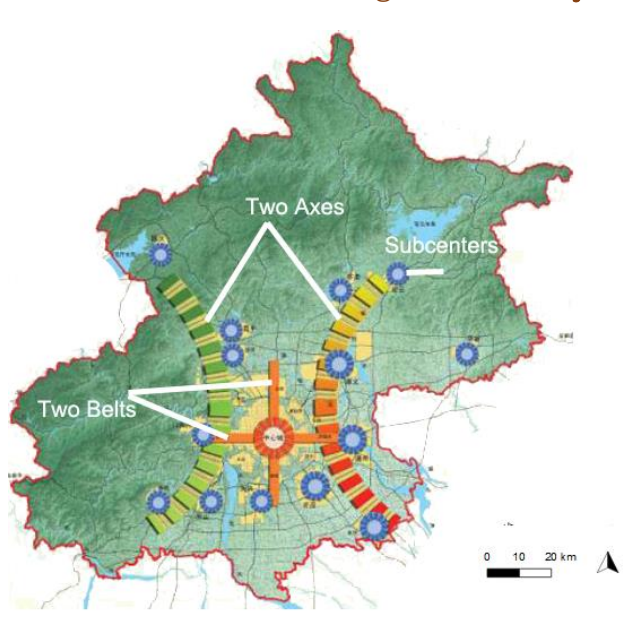

(a)

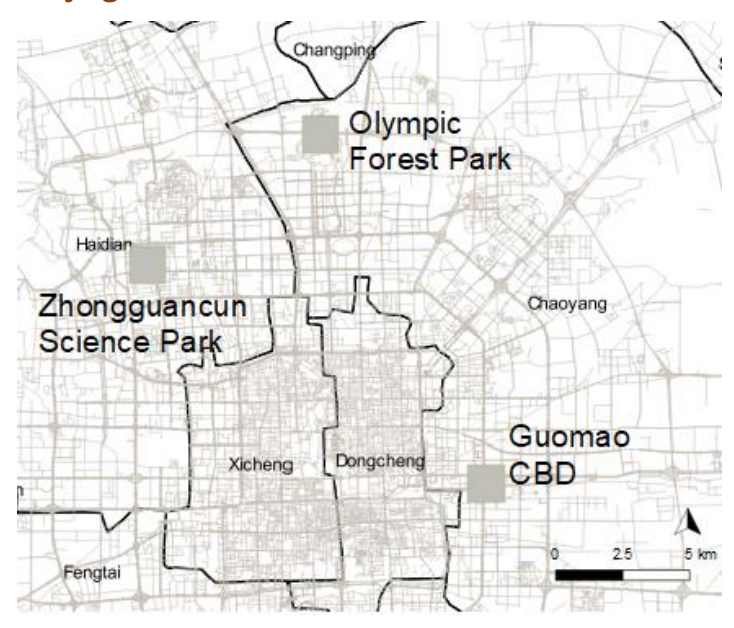

(b)

Source: (a)Beijing Master Plan, 2004; (b) self-elaboration

In 2016, according to the Beijing Municipal Commission of Urban Planning, the urban structure of Beijing will be transformed into "one central city, one deputy city, two-axes and multi-sub-centers". The deputy city undertook part of the administrative function of Beijing.

In summary, as the speed of urban expansion of Beijing is so fast the controversy of the urban structure of Beijing remains, this paper using Weibo data to detect the sub-centers can provide a new sight to analyze the urban structure of the city. Moreover, because the data coverage covers New developing zones and ecological zones, it can evaluate the developmental situation of the whole Beijing area.

\section{Methodology}

\subsection{Research design}

We calculated the cumulative density of Weibo-messages in Beijing to identify Weibo sub-centers. Meanwhile, a comparative study will help us to identify the function of the sub-center. Because it is hard to obtain the latest official document of cadastral information and land use, we made a direct comparison with Google map and Baidu map which is the most popular electronic map in mainland China. The current version map can help us to observe the latest status of land-uses. The third step was to analyze the frequency of Weibo messages in terms of different time periods. Based on the results, this paper built a regression model to distinguish the Weibo sub-centers during the week, 
workdays and weekends, then make an urban contexture analysis of Beijing city. It tried to discuss in which degree Weibo data could reflect the urban tissue, and the type of land uses of these subcenters.

\subsection{Data collection}

Weibo is one of the most popular social media in China, whose functions are similar to Twitter. A user can post words, pictures, mention or talk to other people via this platform. Every message sent by a user is called a "Weibo". Users can create a "nickname" for their Weibo accounts, but all users should register with true identities.

The total users of Weibo are over 500 million in China. According to Weibo Development Report 2014, the main users were among 19-35 years old, accounted for $72 \%$ for total users. The monthly active users have reached 167 million, the whole Beijing area took up 8.7\% of them. Considering the total population was 21.52 million in 2014, it suggests that half of the people in Beijing use Weibo time to time. Therefore, it is reasonable to utilize Weibo data to explore the urban space of the Beijing area.

The API (Application Programming Interface) is a set of routines, protocols, and tools for building software applications. It allows developers and researchers to access the database of an electronic platform. Many popular websites, such as Twitter and Facebook, provide free APIs for the public. Weibo API also provides free resources for researchers, though there are many restrictions. For instance, the maximum number of inquiring data is 1,000 times per day, and one inquiry only can get 2,000 messages. Despite the restrictions, Weibo API offers various open ports of data to researchers: Weibos per user, user's basic information, network relationship of accounts, geographic information, etc. Therefore, we could get a lot of useful information about citizens through Weibo API, especially the port of geo-information allows researchers to explore the dynamic activities in a city.

Figure 3. Monitoring points and its range

\begin{tabular}{|c|c|c|c|c|}
\hline District & Latitude & Longitude & $\begin{array}{l}\text { Monitor- } \\
\text { Radius(km) }\end{array}$ & $\begin{array}{l}\text { Monitoring } \\
\text { Areas(km2) }\end{array}$ \\
\hline Districts of Dongcheng and Xicheng & 39.915974 & 116.385956 & 4.31 & $1 \quad 58.359$ \\
\hline Chaoyang1 & 39.910231 & 116.526678 & 7.63 & 182.894 \\
\hline Chaoyang2 & 40.024454 & 116.473704 & 7.55 & 179.079 \\
\hline Haidian1 & 39.996334 & 116.27558 & 7.56 & 179.553 \\
\hline Haidian2 & 40.089426 & 116.151917 & 3.6 & 40.715 \\
\hline Shijingshan & 39.919546 & 116.205842 & 4 & 50.265 \\
\hline Tongzhou1 & 39.914332 & 116.704191 & 6 & 113.097 \\
\hline tongzhou2 & 39.76988 & 116.73304 & 10 & 314.159 \\
\hline Changping & 40.15804 & 116.355207 & 10.5 & 346.361 \\
\hline Shunyi (airport included) & 40.114097 & 116.662694 & 11 & 380.133 \\
\hline Daxing & 39.696295 & 116.402051 & 11 & 380.133 \\
\hline Fengtai1 & 39.835938 & 116.373859 & 3 & 28.274 \\
\hline Fengtai2 & 39.852911 & 116.282106 & 4 & 50.265 \\
\hline Miyun & 40.403709 & 116.866321 & 10 & 314.159 \\
\hline Fangshan & 39.676711 & 116.090903 & 11 & 380.133 \\
\hline Mentougou & 39.964773 & 115.977905 & 11 & 380.133 \\
\hline Pinggu & 40.175009 & 117.121087 & 11 & 380.133 \\
\hline Huairou & 40.332106 & 116.633393 & 7.5 & 176.715 \\
\hline Yanqing & 40.459453 & 115.97512 & 11 & 380.133 \\
\hline
\end{tabular}

(a) List of monitoring points

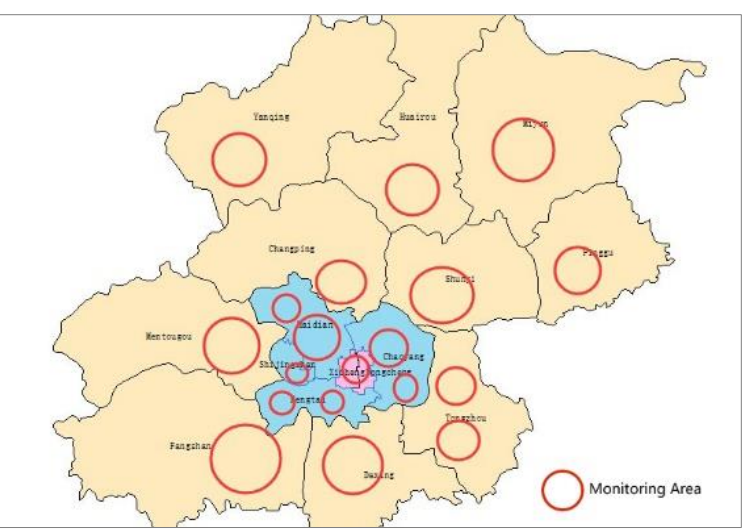

(b) Schematic diagram of the monitoring range

Source: own elaboration

In this study, we utilized the access port of "nearby Weibo" to collect data, which supported to record data around a "monitoring point" (the maximum radius is $11 \mathrm{~km}$ ). The port can track those Weibo messages that users agreed to share their immediate geo-location. The message flow included the original posts and forwarded messages in the monitoring area by chronological order. Because of the limitation of accessing the port per day, it is impossible to cover all areas. We set 19 central points to monitor the data (Figure 3), considering the technical limitations of the application and the current 
situation of build-up areas. After the pre-test of data collection in March and April of 2016, we decided to deliver more tracking frequency and scale to those areas where have had a higher volume of data. Each monitoring circle was restricted in one district and was avoid overlap. We tried to cover the central areas as much as possible. For the outer-districts, such as Huairou, Pinggu, Miyun and the others, the monitoring center-point was set in their central town. The measure of monitor-radius is accomplished by Google Maps' tool which can measure the distance between two points on the map.

The temporal range of data is from 00:00 on the 11th of April to 24:00 on the 17th of April. This timeperiod avoided vacations and festivals of China, thus it could represent the normal situation of Beijing city. After eliminating null data, the total Weibos of the study were 53,967. Three districts appeared data loss in some periods. The amount of Weibo in Haidian district has fallen suddenly on Wednesday due to the data lost from 17:07 of Wednesday to 3:00 on Thursday. Shunyi lost data from 17:52 on Saturday to 16:52 on Sunday. Fengtai lost 16 hours' data from Wednesday to Thursday. However, this loss of data would not affect the analysis greatly, because Shunyi and Fenngtai district generated fewer Weibos in the pre-test, which were below than 15 Weibos per hour. Although Haidian district had a higher frequency, it only lost 10 hours' data. In order to compensate for the loss, the hourly frequency of Weibo of each of the three districts was filled in the lost hours separately.

\subsection{Quadrat analysis}

In order to identify the Weibo sub-centers, it is necessary to divide the city into equal zones to calculate the density of Weibos. Considering that the urban shape of Beijing city is squared and composed of orthogonal roads (Figure 4), it is reasonable to adopt quadrats to calculate the Weibo density.

Figure 4. Detail of Beijing urban tissue

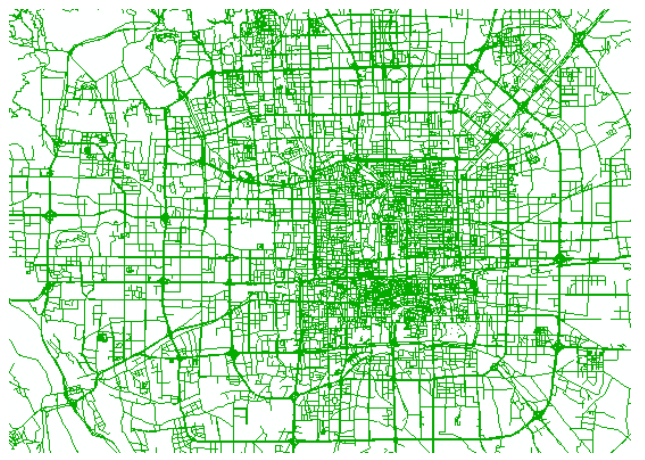

(a) the urban shape of Beijing within the 5 th belt

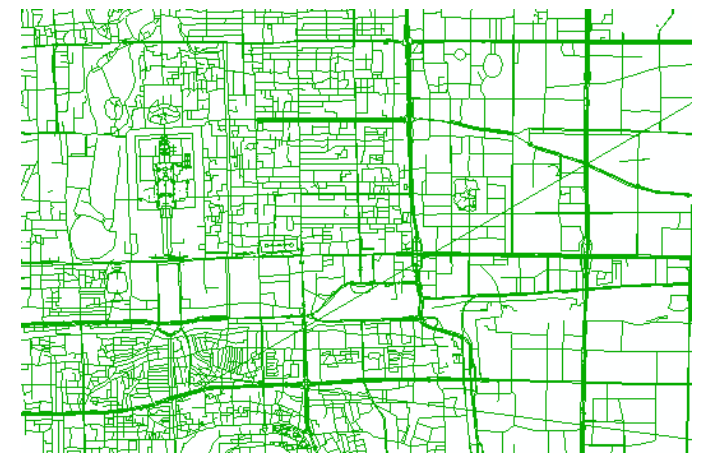

(b) A piece of the urban tissue of Beijing

Source: own elaboration

The more points gathered in a quadrat; the higher the density of the quadrat. Therefore, the size of the grid plays a pivotal role in the analysis. McDonald et al. (1994) used $1.29 \mathrm{~km}^{2}$ of a grid as their research unit in Chicago. Giuliano et al. (1991) used 'transportation analysis zones' which is defined by the California Association of Government (SCAG). The average area of analysis zone is about $8 \mathrm{~km}^{2}$. McMillen et al. (2003) used a quarter square mile (about $0.65 \mathrm{~km}^{2}$ ) as the basic unit of observation in Chicago, because the small unit can find out those low-density regions in the midst of high-density areas. Our unit of the grid is determined by a statistical method. According to the study of Griffith and Amrhein (1994), the formula of optimized quadrat area is:

$$
\text { Quadrat area }=2 \mathrm{~A} / \mathrm{q}
$$

ACE, 15 (4.3) CC BY-ND 3.0 ES | UPC Barcelona, Spain |Analysis of the Spatial Structure of Beijing from the point view of

Weibo Data. DOI: http://dx.doi.org/10.5821/ace.15.43.9302 
$A$ represents the surface of the studied area, $q$ is the number of points. The studied area is calculated by the actual monitoring area, not the whole urban area. Therefore, the area of studied range is calculated by the formula of the circle:

$$
\text { Quadrat area }=\frac{\sum_{i=1}^{19} 2 \pi r_{i}^{2}}{q}
$$

where $r$ is the radius of the monitoring radius, $i$ is the serial number of monitoring circle.

The total area of monitoring circles equals $4,314.70 \mathrm{~km}^{2}$, and the number of points (i.e. Weibo messages) is 53,967 , thus the statistical optimum quadrat area is $0.16 \mathrm{~km}^{2}$ (i.e. the length of the side is $0.4 \mathrm{~km}$ ). Based on this size, we also expand the length of side triple and sextuple respectively for comparative reasons, because the size of the units in previous researches is larger than the one we calculated (Table 1). The medium one is similar to previous studies. The largest one significantly reduces the percentage of minimum value, however, it cannot match the boundary of the monitoring circle very well. It enlarges the total monitoring area. Therefore, the largest size is excluded.

Table 1. Three different sizes of quadrat

\begin{tabular}{|c|c|c|c|c|c|c|}
\hline $\begin{array}{l}\text { Quadrat } \\
\text { side }(\mathrm{km})\end{array}$ & $\begin{array}{l}\text { Number of } \\
\text { Quadrats }\end{array}$ & $\begin{array}{l}\text { Minimum nu } \\
\text { in one quadr }\end{array}$ & & $\begin{array}{l}\text { Maximum } \\
\text { number }\end{array}$ & Mean & $\begin{array}{l}\text { Standard } \\
\text { Deviation }\end{array}$ \\
\hline 0.4 & 6952 & 1 & $33.5 \%$ & 442 & 7.76 & 16.75 \\
\hline 1.2 & 1814 & 1 & $23 \%$ & 887 & 29.53 & 69.22 \\
\hline 2.4 & 705 & 1 & $16 \%$ & 1831 & 75.98 & 196 \\
\hline
\end{tabular}

Note: the quadrats that do not contain Weibo messages were excluded from the sum of quadrats.

Source: own elaboration

Next, Anselin Local Moran's I (Arcgis 10.2) is introduced to test the clustering degree of points based on medium and small grids respectively. If there is no significant clustering area, or the distribution is dispersed, it indicates that Weibo data is probably useless in detecting the urban structure. Both grids (Figure 5) show strong trends of concentration, however, the medium grid $(1.2 \times 1.2 \mathrm{~km}$ ) (Figure 5-a) fails to distinguish those areas of lower density in the central city. Therefore, we use the small size of the grid as the unit to calculate the density.

Figure 5. Anselin Local Moran's I Result

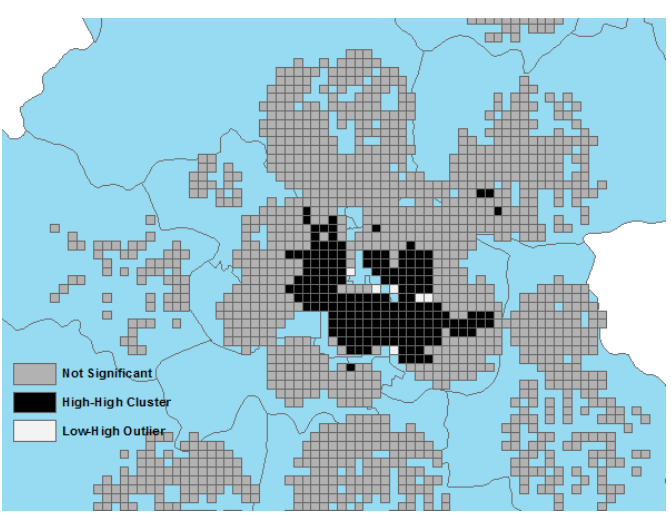

(a) Grid: $1.2 \times 1.2 \mathrm{~km}$

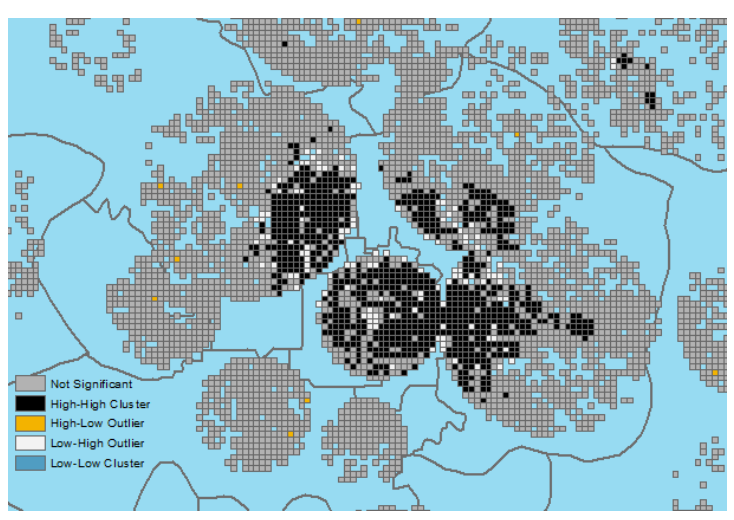

(b) Grid: $0.4 \times 0.4 \mathrm{~km}$

Source: own elaboration

ACE, 15 (4.3) CC BY-ND 3.0 ES | UPC Barcelona, Spain |Analysis of the Spatial Structure of Beijing from the point view of

Weibo Data. DOI: http://dx.doi.org/10.5821/ace.15.43.9302 


\subsection{Identification of Weibo sub-centers}

This paper tries to identify Weibo sub-centers in four periods - workdays (Monday to Friday, from 8:00 to 20:00), nights (Monday to Friday, from 23:00 to 6:00), the weekend and the whole week. A potential sub-centers should satisfy two criteria: 1) it should be located in the High-High cluster which is based on the Anselin Local Moran's I Result; 2) the density of the potential area should be above the mean Weibo density of the HH cluster plus one Standard Deviation. The first condition selects out those high active grids. The second condition excludes those grids of lower density in the $\mathrm{HH}$ clusters. After the selecting out those cells that satisfy the criteria, we aggregate these cells into potential sub-centers through nearest-neighbor principle. The standard of aggregation is that the distance between two qualified grids is equal or less than $0.4 \mathrm{~km}$.

As we detect sub-centers using the density approach, there are three major methods (Roca Cladera et al., 2009): reference thresholds, parametric methods, non-parametric methods. The reference threshold is to set a statistical or numerical threshold to select out sub-centers, such as a threshold of the density of employment or density of workplaces (Garcia-López and Muñiz, 2010; Giuliano and Small, 1991). This method can be used to compare the results of a single city in different periods. However, when the stricter statistically rigorous is demanded, the parametric or non-parametric modelling has more advantages. Since the monitoring range of our dataset does not cover the whole of Beijing, it is hard to estimate a continuous surface of density to introduce the non-parametric model. Therefore, we adopted the classic negative exponential model (McDonald and Prather,1994) to identify Weibo sub-centers. Firstly, we assume that the distribution of density of Weibo also follows the similar pattern of the employment distribution - it decreases as the distance to the city center or CBD increases. Secondly, our model only restricts to the potential Weibo sub-centers:

$$
D\left(x_{i}\right)=D_{0} e^{-\alpha x_{i}+b}
$$

$D\left(x_{i}\right)$ corresponds to the Weibo density of a given $i$ potential sub-center, and $x_{i}$ is defined as the Euclidian distance from the mean center of the $i$ potential sub-center to the sub-center which has the highest Weibo density (which in turn is assumed to be the Beijing' CBD). $\alpha$ is the slope of the density that is reduced departing from the Weibo CBD. Since the negative exponential model is nonlinear, we transform it into the linear form for calculation purposes:

where $C=\ln D_{0}+b$

$$
\ln D\left(x_{i}\right)=-\alpha X i+C
$$

Finally, based on unstandardized residual values from the model, two thresholds are introduced to the test of identification of the sub-centers: 1) the residual value of a confirmed sub-center should be positive and is equal or above the mean value of all residual values plus one standard deviation; 2) the residual value of a confirmed sub-center is positive and above the mean value of all residual values. The final threshold is decided by the analysis of the social-economic profile and the actual urban land use.

\section{Results for the identification of Weibo sub-centers}

\subsection{Temporal variation of Weibo messages}

Figure 6 (a) shows the variation of Weibo activities along one week. The Saturday and Monday has the highest number of Weibos. The least active day is the Friday. The Weibo activity is slightly higher at the weekend than during workdays (Figure 6 (b)). According to the 2015 Weibo Search Engine WhiteBook, the first and second rank of searching frequency are news and celebrities. It indicates that

ACE, 15 (4.3) CC BY-ND 3.0 ES | UPC Barcelona, Spain |Analysis of the Spatial Structure of Beijing from the point view of 10 Weibo Data. DOI: http://dx.doi.org/10.5821/ace.15.43.9302 
people mainly use Weibo as a source of information and as an entertainment application. In terms of the hourly Weibo activities (Figure 6 (c)), the most active period is from 21:00 to 0:00 on workdays and the weekend. Therefore, it is reasonable to deduce that the majority of users enjoy their leisure time after 21:00 pm. The average Weibo activities on workdays are higher than the weekend before 12:00 am. After 14:00, the average frequency of weekend is higher than the workdays. It reflects the habitual differences between workdays and weekend.

Figure 6. Temporal distribution of Weibo activities

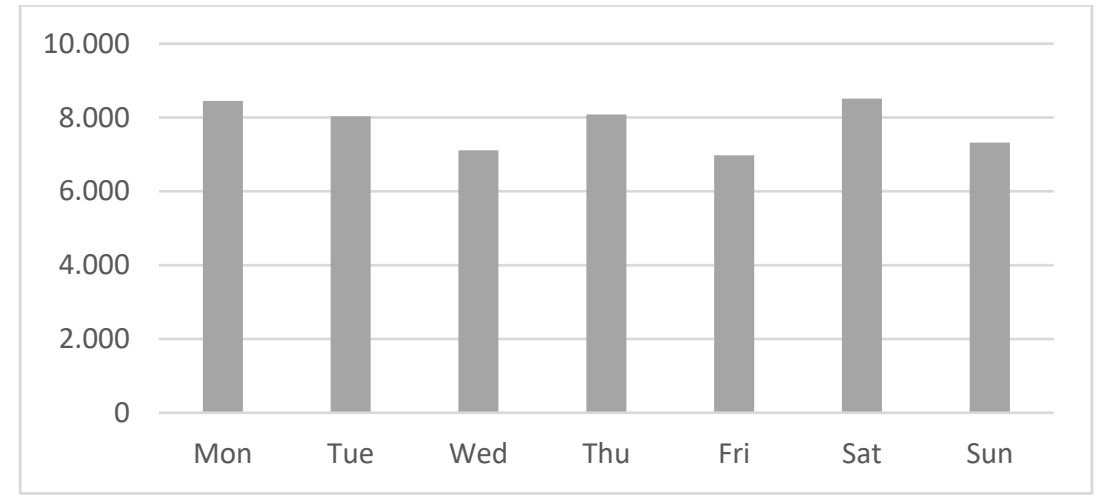

(a) Distribution of Weibos per day

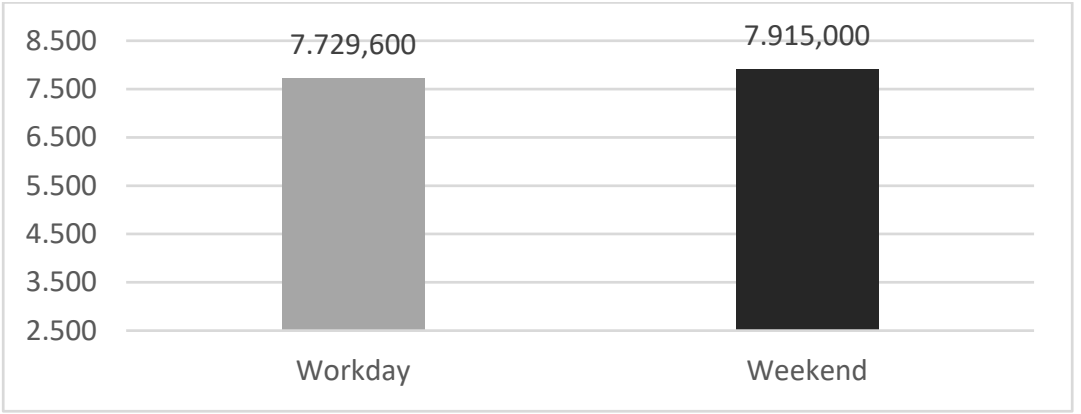

(b) Daily average frequency of Weibos during workdays and the weekend

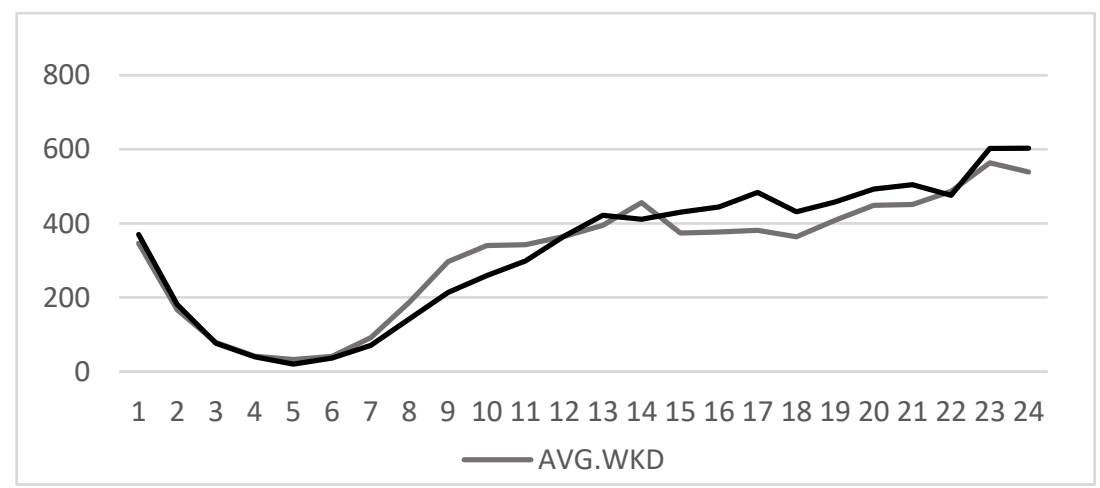

(c) Average frequency of Weibo messages per hour

Source: own elaboration

\subsection{Spatial distribution of Weibo density}

Figure 7 shows that grids with high-density mainly concentrated in the central zone and in the expanded functional zone. There is a decreasing tendency of Weibo density from the central area to

ACE, 15 (4.3) CC BY-ND 3.0 ES | UPC Barcelona, Spain |Analysis of the Spatial Structure of Beijing from the point view of 11 Weibo Data. DOI: http://dx.doi.org/10.5821/ace.15.43.9302 
the periphery. The density of the developing zone and ecological conservation zone is lower than the central city in general. It is coincident with the lower density of population and urban constructions in these areas.

Figure 7. 3D Weibo density panorama

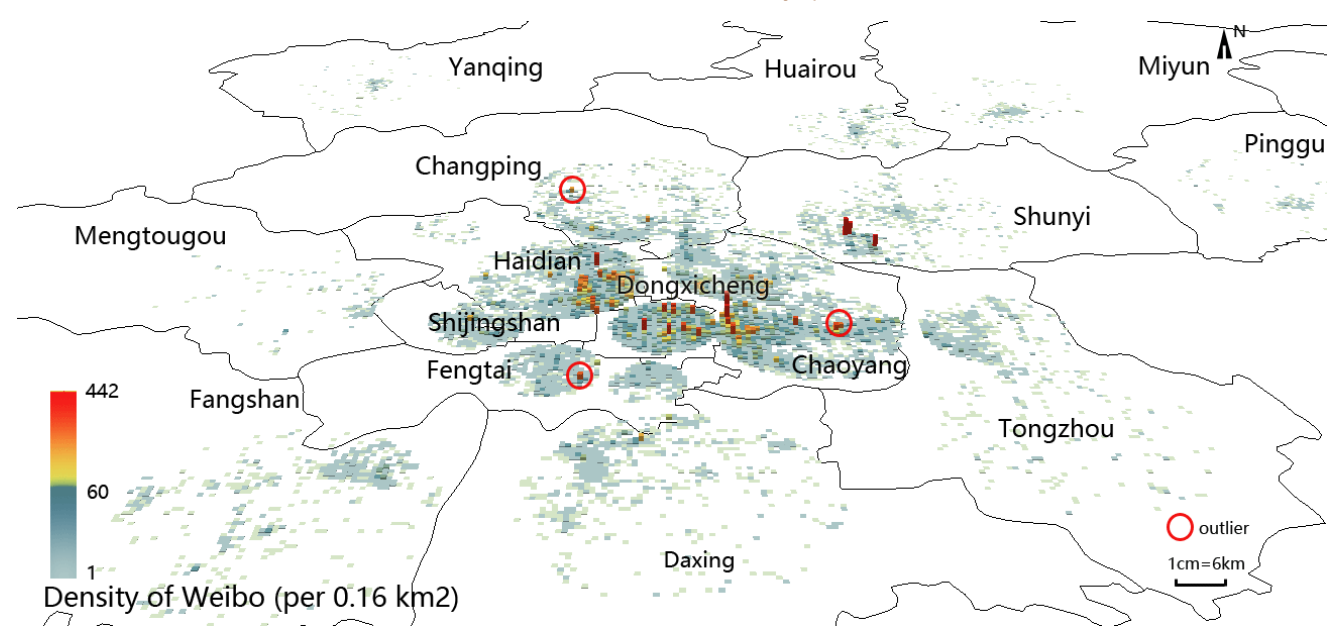

Source: own elaboration

Besides the airport in the Shunyi district, there are three places of higher density which surrounded by low-density cells. Compared to the actual urban contexture, they are located in universities, such as Capital University of Economics and Business in Fengtai district, the Communication University of China and Beijing International Studies University in Chaoyang district, and the zone of a university in Changping district.

Figure 8. 3D view of Weibo density in the central area of Beijing

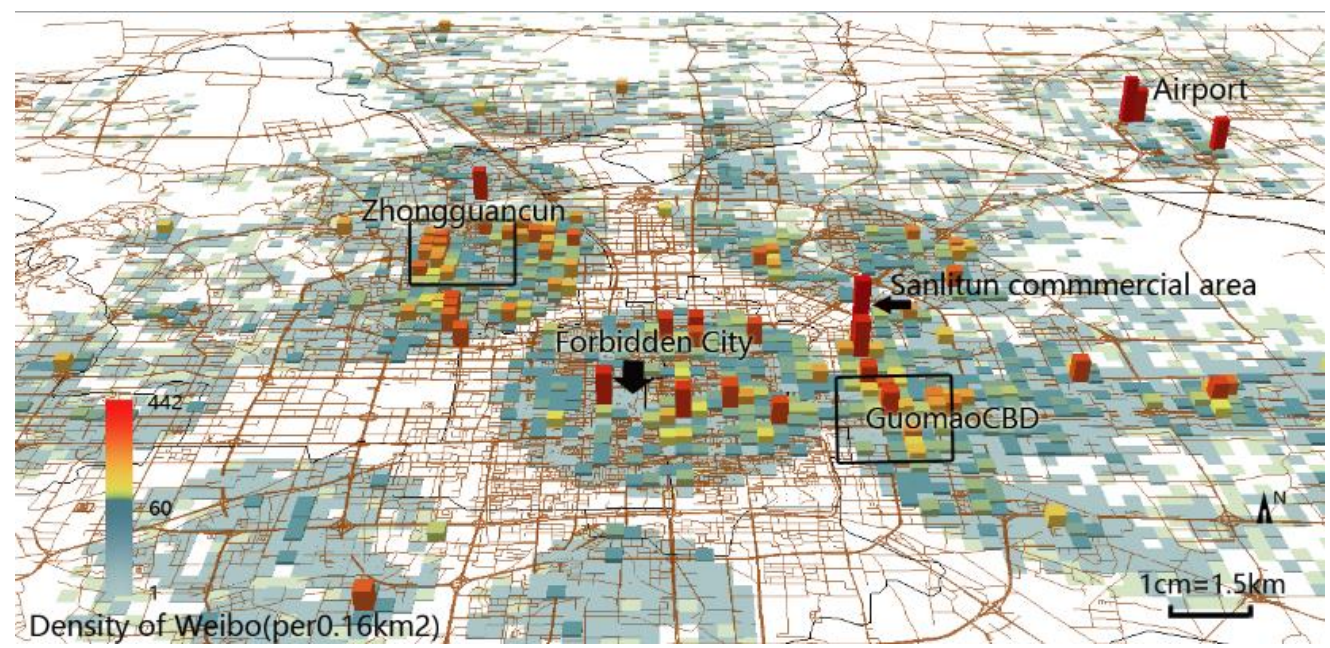

Source: own elaboration

If we check the density map closely (Figure 8), the distribution of density in the central area is actually variable from place to place, rather than the same intensity. From the Guomao CBD to Sanlitun, there is a high-density area along with the third ring road, because many office towers are constructed in the area. Figure 9 contains a partial view of Guomao CBD along with the third ring road. The CCTV headquarter, China Merchants Tower and many other famous towers all gather in these streets.

ACE, 15 (43) CC BY-ND 3.0 ES | UPC Barcelona, Spain |Analysis of the Spatial Structure of Beijing from the point view of 


\section{ACE Architecture, City and Environment}

e-ISSN $1886-480$

Figure 9. 3D view of urban contexture in the Guomao CBD area

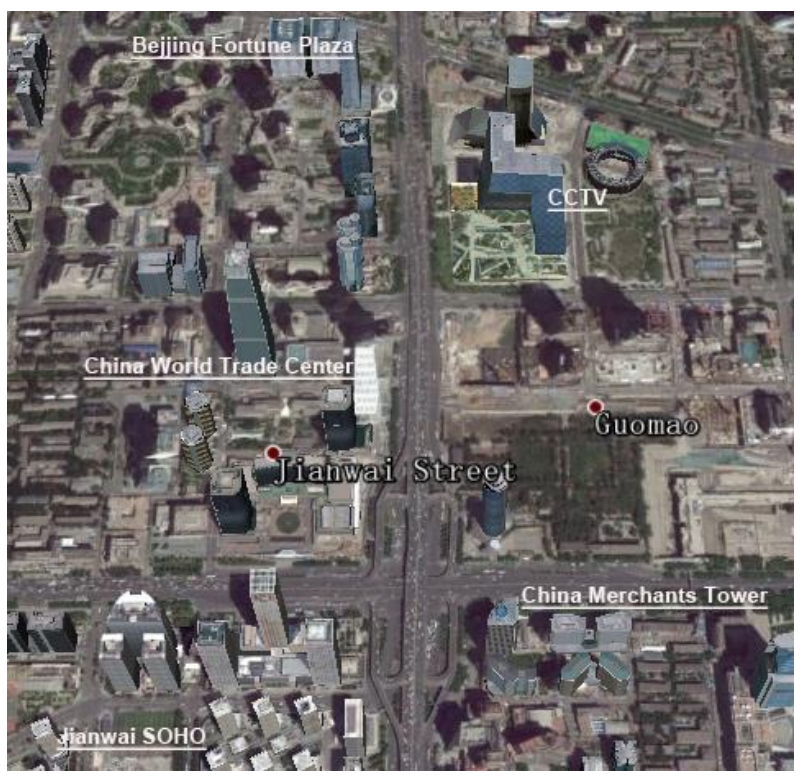

Source: Google earth

Within the second ring road, the density around Forbidden City actually was not very high, because the central government and Beijing government are located in the area (Figure 10). Tian'anmen Square and Mausoleum of Mao Zedong are in front of the Forbidden City. Thousands of tourists visit these two places every day, thus the density rises ${ }^{2}$. Similarly, the higher density in the northern part of the traditional center was formed by tourism, because many Hutong (a kind of typical residential construction and culture of Beijing) are located here.

Figure 10. 3D view of Weibo density in traditional city center and Haidian

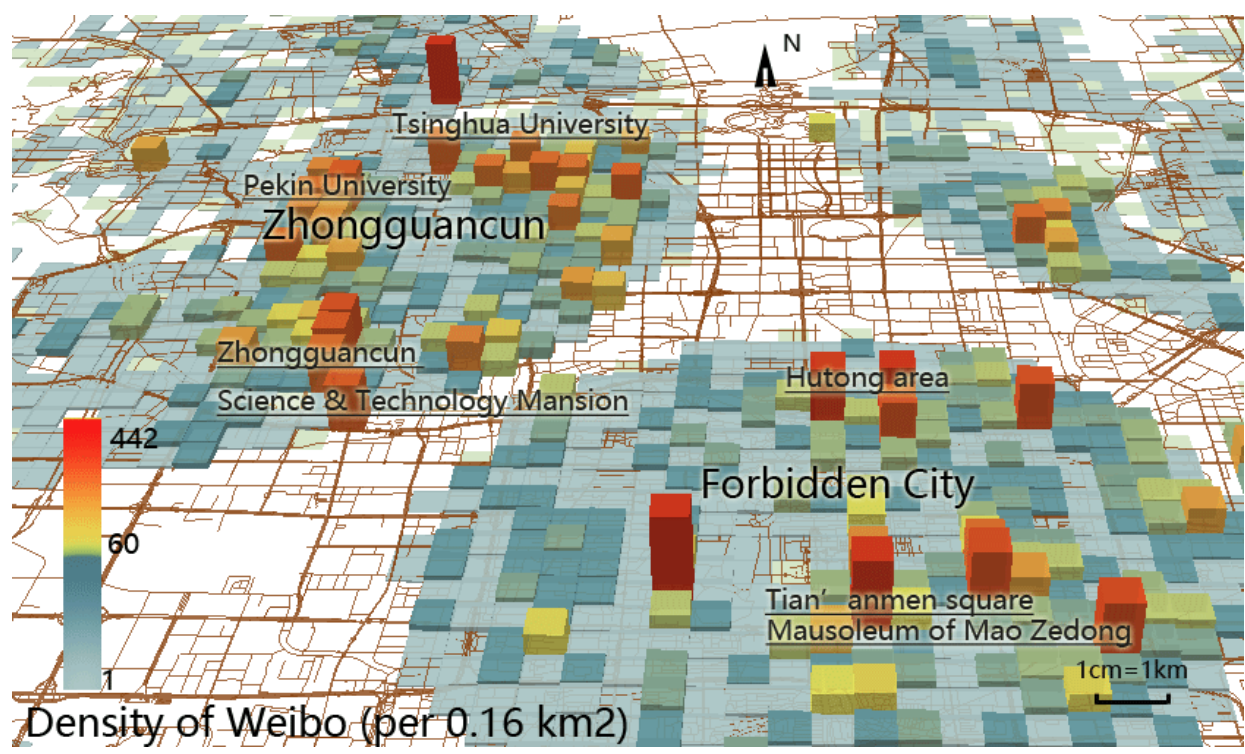

Source: own elaboration

${ }^{2}$ As the roaming service of mobile is very cheap even free (depends on the type of contracts) in China, the willingness that tourist use Weibo is not affected by mobile roaming.

ACE, 15 (4.3) CC BY-ND 3.0 ES | UPC Barcelona, Spain |Analysis of the Spatial Structure of Beijing from the point view of 
In the Haidian district, universities and office areas are the main types of land use. In the past two decades, Zhongguancun has gathered nearly 20,000 high-technology enterprises, including Lenovo and Baidu. The higher density grids distribute along with Zhongguancun Streets and Chengfu Road in general. It matches the distribution of technological companies in this area. According to the introduction on Zhongguancun Science Park's official website, the distribution of these companies approximately starts from Zhongguancun Street, then goes up to Chengfu Road, forms an "F"-shape area.

\subsection{Identification of Weibo sub-centers in Beijing}

Figure 11 shows that all potential Weibo sub-centers are located in Chaoyang, Haidian, Dongcheng, Xicheng and Shunyi Districts. The potential Weibo sub-centers of one week are less than other periods because the average density is the highest (Table 2) so that only 72 grids satisfy with the criteria abovementioned, which only account for $2 \%$ of total grids. The potential sub-centers of days (Figure 11-(b)) and nights (Figure 11-(c)) of workdays are quite close to each other. However, the density of Weibo activities is weaker in the night.

Table 2. Statistical description of potential Weibo sub-centers and distance

\begin{tabular}{|l|l|l|l|l|l|l|l|l|l|l|}
\hline \multicolumn{4}{|l|}{ Ln_Density } & \multicolumn{3}{|l|}{ Distance to Weibo-CBD(km) } \\
\hline & Mean & Std. & Range & Min & Max & Mean & Std. & Range & Min & Max \\
\hline One week & 6.569 & 0.264 & 0.921 & 6.271 & 7.193 & 6.626 & 3.952 & 13.321 & 0.000 & 13.322 \\
\hline Weekend & 5.682 & 0.376 & 1.647 & 5.267 & 6.913 & 6.394 & 3.774 & 14.882 & 0.000 & 14.882 \\
\hline Day_workday & 5.887 & 0.318 & 1.014 & 5.546 & 6.560 & 7.245 & 3.964 & 14.882 & 0.000 & 14.882 \\
\hline Night_workday & 5.002 & 0.212 & 0.722 & 4.666 & 5.388 & 7.602 & 3.934 & 14.834 & 0.000 & 14.834 \\
\hline
\end{tabular}

Source: own elaboration

In terms of land uses (Table 3), it changes with different periods. Mixed area, university, transportation hub, and tourist attraction show more active in workdays, while sub-centers of university decrease in the weekend. None of the potential sub-centers belong to the residential area in the time span of one week (Figure 11- (a)) and day-period of workdays (Figure 11- (b)).

Commercial and office areas $(1,5,9,22,27)$ are the major types of land use for Weibo sub-centers considering the complete week period. In the day-period of workdays, two important railway stations-Beijing Northern Station (23) and Beijing Eastern Station (8) appear as potential Weibo subcenters. It is possibly caused by their function as transportation hubs that connect with Beijing suburban trains. Especially, many Interprovincial trains pass through Beijing Eastern Station, thus it is also an active area during the night.

Compared with the day-period, besides the two universities in the eastern part $(18,19)$, there are more potential Weibo sub-centers in the night of workday concentrated in the northwest part where many universities are located. It implies that the main active users during the night-period are students of universities. 


\section{ACE Architecture, City and Environment}

Figure 11. Distribution of potential Weibo sub-centers in Beijing

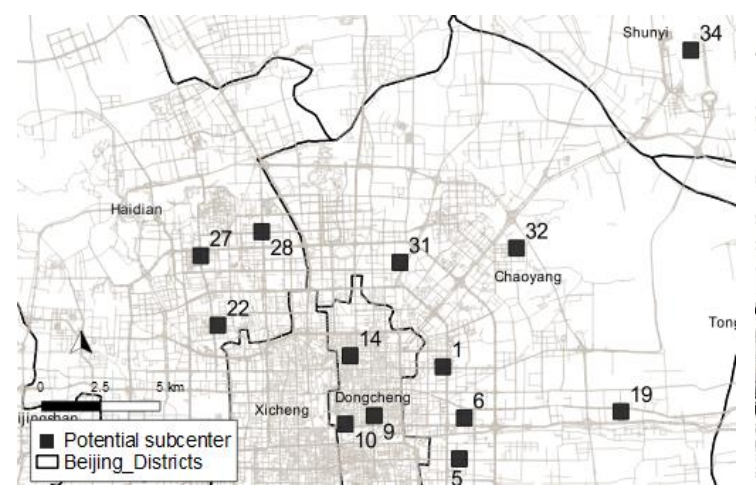

(a) One-week

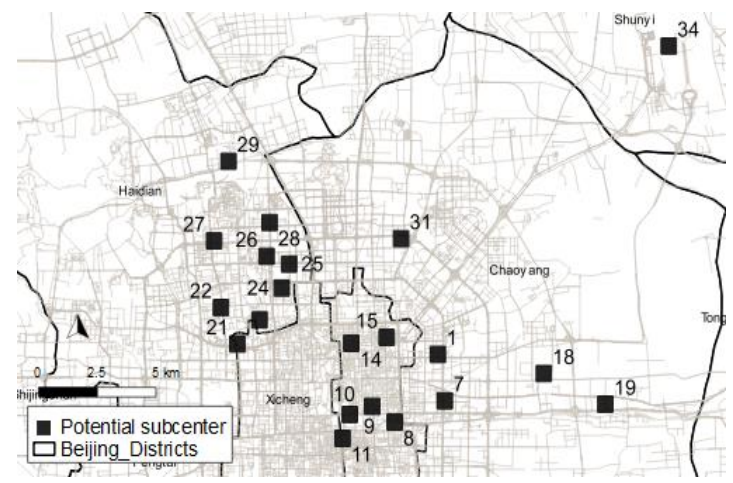

(c) Night of workdays

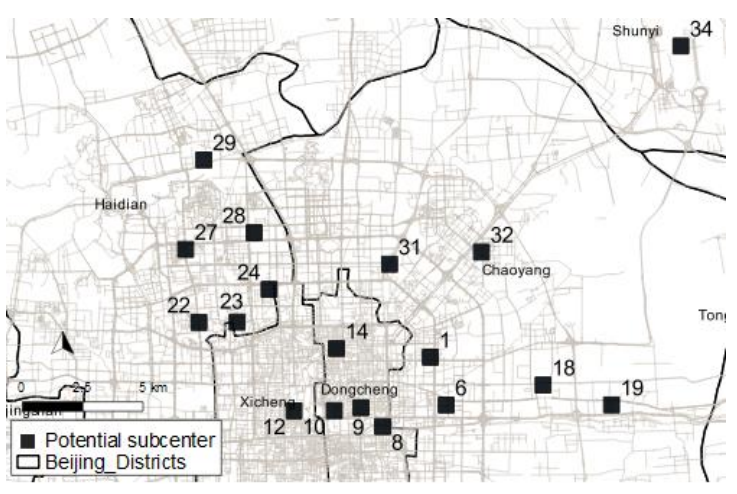

(b) Day of workdays

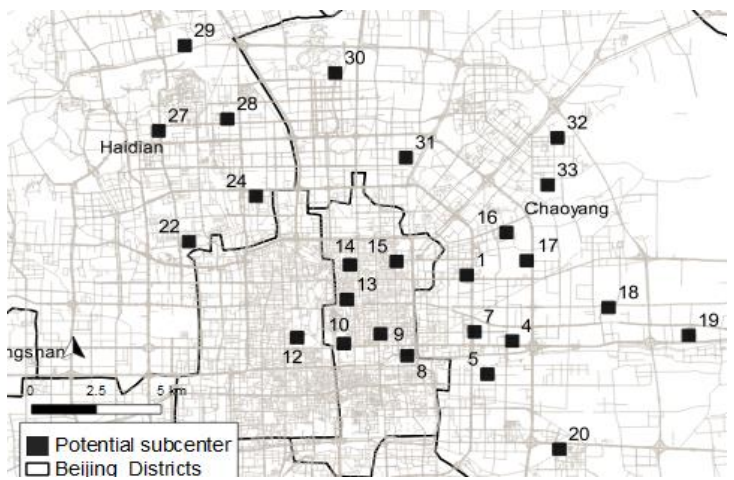

(d) The weekend

Source: own elaboration

During the weekend (Figure 11-d), tourist attractions $(10,13,14)$ and recreational areas $(16,17,20,30,32)$ account for $40 \%$ of total potential sub-centers; for example: 10 is Tian'anmen Square, 13 and 14 are Hutong areas, and 16 is the 798 Art Zone. Three residential places $(5,16,31)$ are shown as potential sub-centers. Some recreational places only appear active at the weekend. For example, 20 is an amusement park, and 30 is the Olympic Forest Park. Both of them are far away from the city center, thus such Weibo activity is probably generated from the users who live in Beijing and visit such venues.

Moreover, it is worth noticing that the highest density area locates at the Beijing International airport (Figure 11-(a)(b)(c), 34) during the one week-period and workdays-period. It may be caused by its enormous passenger flows. According to $\mathrm{ACl}^{\prime} \mathrm{s}$ data ${ }^{3}$, Beijing airport got the No.2 rank of total passenger traffic among 1,144 airports worldwide in 2015. The enplaning and deplaning passenger was nearly 90 million in 2015. Thus, Beijing airport is a functional hub on a national scale without any doubt.

However, the airport is excluded from our regression model aimed at confirming Weibo sub-centers, because it is unreasonable to set the airport as the central point of the model and its importance corresponds to the national interests, not just the intra-urban one. Furthermore, in a preliminary model test, the inclusion of the airport reduces the coefficient of determination ( $R$ square) significantly, due to its highest density and further distance to the central city (about $25.5 \mathrm{~km}$ ).

${ }^{3} \mathrm{ACl}$ : Airports Council International. Data source link: http://www.aci.aero/News/Releases/MostRecent/2016/04/04/ACl-releases-preliminary-world-airport-traffic-rankings- 
Table 3. The land use type of overlapping potential sub-centers

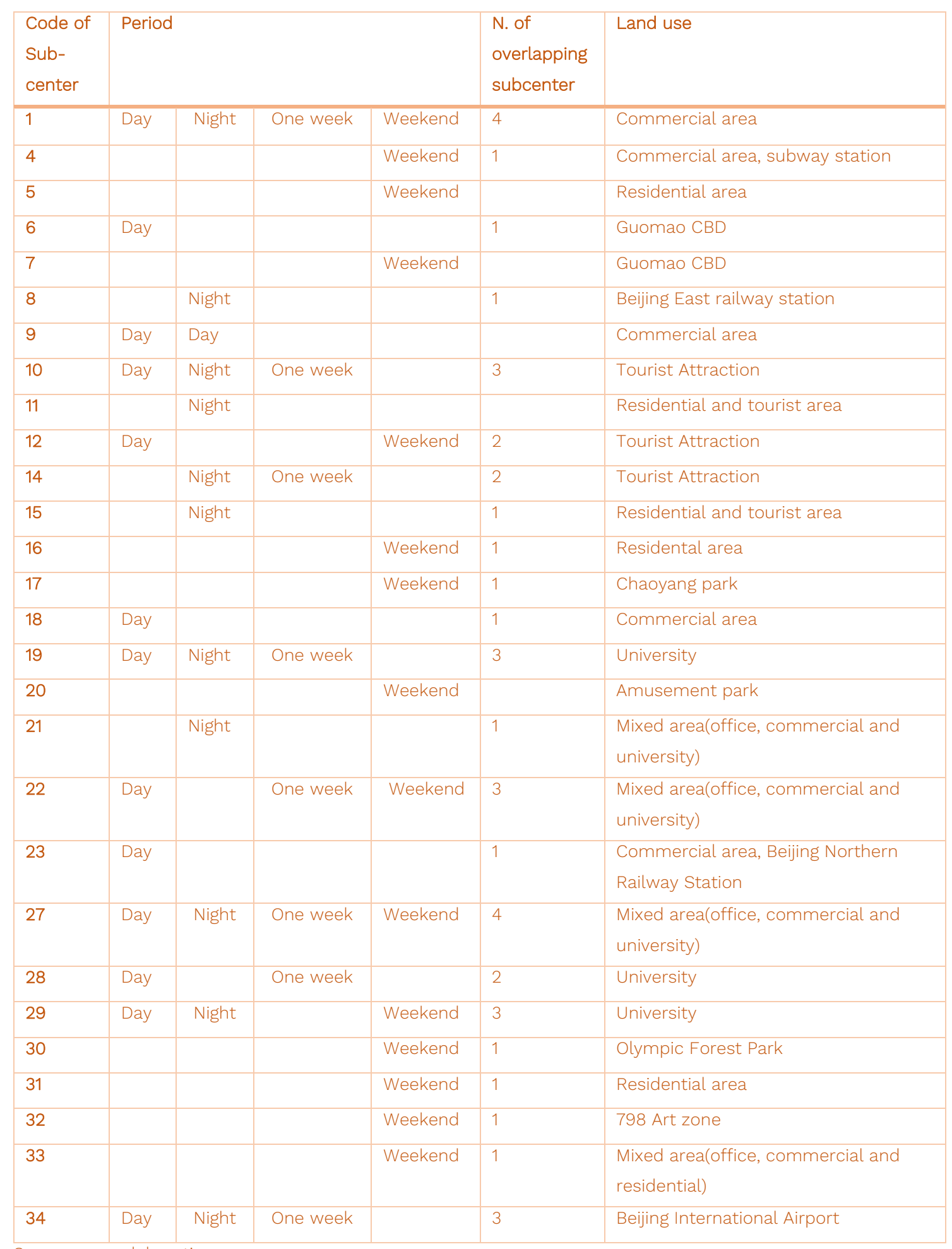

Source: own elaboration 
Now, we adopt the logarithmic linear regression model to test these potential Weibo sub-centers. Rather than the traditional central point, the potential Weibo sub-center which has the highest average density of Weibo (Weibos per $\mathrm{km}^{2}$ ) is chosen as the center to calculate the distance (i.e. Weibo-CBD). Therefore, the most relevant potential Weibo sub-center - the Sanlitun commercial area is set as the central point to calculate the distance. It has the highest density of all periods after the airport, which is a famous landmark in Beijing which consists of popular culture hubs, commercial centers, and more than 200 bars.

Table 4 is the summary of models for each different period. At the $90 \%$ confidence level, the only model that resulted in an acceptable statistical significance is that of the weekend Weibo density. The distance could explain $14.3 \%$ of the variation of Weibo density during the weekend. In terms of one-week period, although the model distance from the point of comparative highest Weibo density could explain $21 \%$ of the variation of Weibo density, the statistical significance rejects the model result. However, the model is completely ineffective for the two periods of workdays, which adjusted $\mathrm{R}^{2}$ is negative. It is caused by the $\mathrm{R}^{2}$ is almost zero which means that the distance cannot explain the variance of Weibo activities during the workday. One possible explanation is that those potential subcenters in Haidian districts impact the model because they were almost absent in the weekend period (Figure 11(d)).

Table 4. Model Summary for the four periods

(a) Model summary

\begin{tabular}{|l|l|l|l|l|l|}
\hline Model & $\mathrm{R}^{2}$ & Adjusted R & $\begin{array}{l}\text { Std. Error of the } \\
\text { Estimate }\end{array}$ & Sig. \\
\hline One week & 0.210 & 0.132 & 0.246 & 2.671 & .133 \\
\hline Day_Workday & 0.000 & -0.660 & 0.328 & .004 & .953 \\
\hline Night_workday & 0.030 & -0.022 & 0.221 & 1.616 & .230 \\
\hline Weekend & 0.143 & 0.106 & 0.356 & 3.853 & .062 \\
\hline
\end{tabular}

(b)Coefficients

\begin{tabular}{|c|c|c|c|c|c|c|}
\hline \multirow[t]{2}{*}{ Model } & & \multicolumn{2}{|c|}{$\begin{array}{l}\text { Unstandardized } \\
\text { Coefficients }\end{array}$} & \multirow{2}{*}{$\begin{array}{l}\text { Standardiz-ed } \\
\text { Coefficient-s } \\
\text { Beta }\end{array}$} & \multirow[t]{2}{*}{$\mathrm{t}$} & \multirow[t]{2}{*}{ Sig. } \\
\hline & & B & Std. Error & & & \\
\hline \multirow[t]{2}{*}{ One week } & (Constant) & 6.773 & .143 & & 47.264 & .000 \\
\hline & Distance(km) & -.031 & .019 & -.459 & -1.634 & .133 \\
\hline \multirow[t]{2}{*}{ Day_workday } & (Constant) & 5.896 & .170 & & 34.721 & .000 \\
\hline & Distance(km) & -.001 & .021 & -.016 & -.060 & .953 \\
\hline \multirow[t]{2}{*}{ Night_workday } & (Constant) & 3.250 & .106 & & 30.601 & .000 \\
\hline & Distance(km) & -.011 & .012 & -.195 & -.844 & .410 \\
\hline \multirow[t]{2}{*}{ Weekend } & (Constant) & 5.924 & .142 & & 41.630 & .000 \\
\hline & Distance $(\mathrm{km})$ & -.038 & .019 & -.379 & -1.963 & .062 \\
\hline
\end{tabular}

Source: own elaboration

ACE, 15 (43) CC BY-ND 3.0 ES | UPC Barcelona, Spain |Analysis of the Spatial Structure of Beijing from the point view of 
Such a lower explanatory percentage possibly indicates that the urban structure of Beijing belongs to a polycentric model from the perspective of Weibo activities. However, another possibility is that the directions of the distribution of these potential points may influence the result. In other words, the development of sub-centers is not exactly symmetrical. Thus, we set point 1 as the center to divide the map into four quadrants (Figure 12). This division separates the Guomao CBD, Zhongguancun area, traditional center and airport into different quadrants, thus it can alleviate the effect of opposed directional development trends. Because the 34th - airport is not involved in the model test, the 32nd is added into the second quadrant. The confirmed sub-center is the sum of each quadrant's result.

Figure12. The classification of workday's potential sub-centers

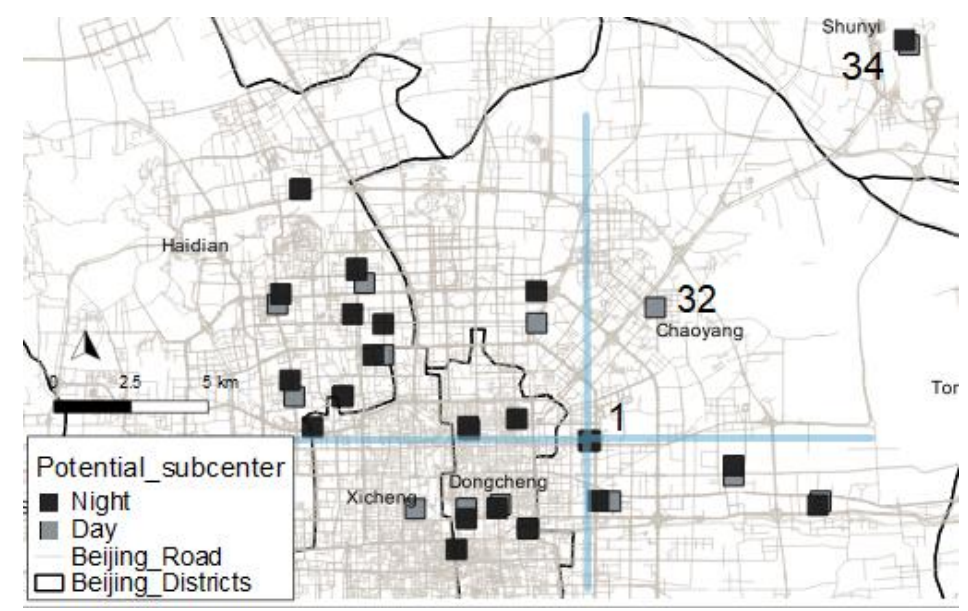

Source: own elaboration

However, none of the models is shown statistical signifance (Table 5). The model is still completely ineffective during the day-period. The adjusted $R^{2}$ of the night period is improved after the classification because it eliminates the effect of different directional development trends. The potential candidates of the fourth quadrant have a lower density of Weibo than the candidates of other quadrants which are located at a similar distance. The first and second quadrant suffer the least influence from the distance. Because their average density is very high, more or less equals to the Guomao CBD area, but they are far away from the central point. Compared with the fourth quadrant, the third quadrant also presents that the distance has weak influence. One possible reason is that the third quadrant belongs to the traditional center of the city, and the fourth quadrant is near to the suburban area.

Table 5. Model Summary of Workdays and nights of workdays

\begin{tabular}{|l|l|l|l|l|}
\hline Model & & $\begin{array}{l}\text { 1st\&2nd } \\
\text { quadrant }\end{array}$ & 3rd quadrant & $\begin{array}{l}\text { 4th } \\
\text { quadrant }\end{array}$ \\
\hline \multirow{2}{*}{ Day workday } & $\mathrm{R}^{2}$ & 0.008 & 0.051 & 0.203 \\
\cline { 2 - 5 } & Adjusted R & -0.116 & -0.265 & -0.196 \\
\hline & Std. Error of the Estimate & 0.378 & 0.435 & .509 \\
\hline & F & .063 & .163 & .550 \\
\hline & Sig. & .809 & .714 & 0.356 \\
\hline \multirow{2}{*}{ Night workday } & $\mathrm{R}^{2}$ & 0.128 & 0.472 & 0.034 \\
\hline
\end{tabular}

ACE, 15 (4.3) CC BY-ND 3.0 ES | UPC Barcelona, Spain |Analysis of the Spatial Structure of Beijing from the point view of 


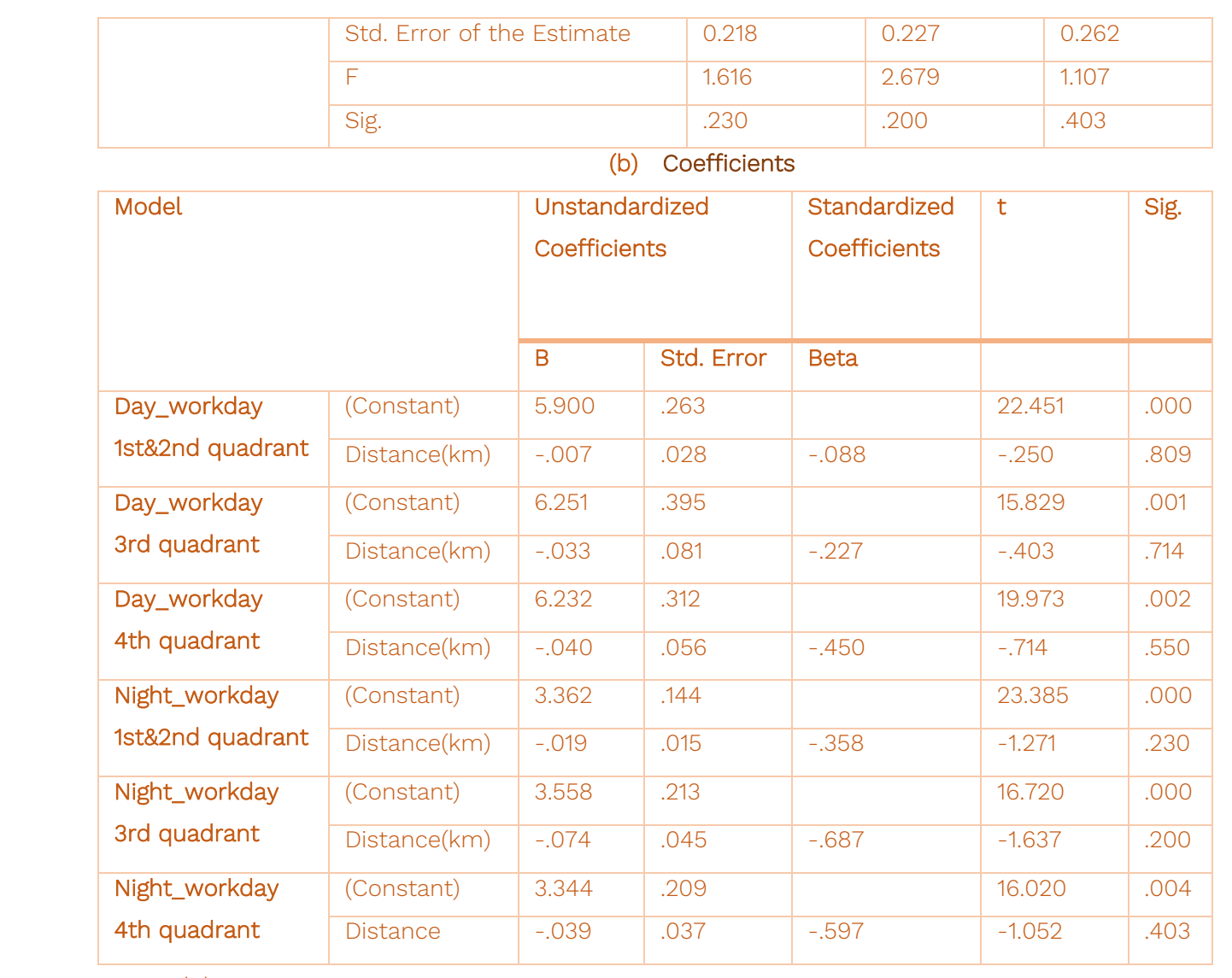

Source: own elaboration

In summary, the only clear spatial trend of Weibo density is the weekend in terms of the model results. It is probably caused by the spatial diversity of Weibo density in these periods. Except for the weekend, the variation of Weibo density is too small to present the evident correlation with the distance. The Weibo density has the largest variation in the weekend (Table 2), which standard deviation is nearly double that of other periods. On the contrary, the mean distance of all potential sub-centers to the Weibo center is the lowest at the weekend.

Table 6. The tested sub-centers of weekend based on two standards

\begin{tabular}{|l|l|l|}
\hline & Standard & Sub-center \\
\hline $\mathbf{1}$ & Positive Residual $\geq$ Mean of all residuals +Std. Deviation & $1,12,31$ \\
\hline $\mathbf{2}$ & Positive Residual $\geqslant$ Mean of all residuals & $1,4,12,14,18,22,27,29,31$ \\
\hline
\end{tabular}

Source: own elaboration

Therefore, we only select the final Weibo sub-centers at the weekend (Table 6). The confirmed Weibo sub-centers at the weekend are the numbers of 1, 12, and 31 following the stricter standard, while there are eight sub-centers if we use the mean-standard. The stricter one appears one commercial areas (1), one tourist attraction (12) and a residential area (31). Combined with the actual socialeconomic profiles, we tend to adopt the mean value as the standard of selecting sub-center. The number 18 (Table 7) is a shopping mall. The number 12 and 14 are in the traditional urban center. The number 22 and 27 are areas of mixed land uses and located in Zhongguancun, Haidian district. The Haidan district accounts for $17.9 \%$ of total permanent residents of Beijing in 2014. Moreover, Zhongguancun is a huge employment center as well as an important commercial area of Beijing.

ACE, 15 (43) CC BY-ND 3.0 ES | UPC Barcelona, Spain |Analysis of the Spatial Structure of Beijing from the point view of 19 Weibo Data. DOI: http://dx.doi.org/10.5821/ace.15.43.9302 
According to Zhongguancun Report 2014, 1,899 million people worked in Zhongguancun area. Considering many companies still operate at the weekend and, it is reasonable to include this area as a sub-center at the weekend.

Table 7. The land use type of confirmed sub-centers at the weekend

\begin{tabular}{|l|l|}
\hline Code of Sub-center & Land use \\
\hline 1 & Commercial area \\
\hline 4 & Commercial area, subway station \\
\hline 12 & Tourist Attraction \\
\hline 14 & Tourist Attraction \\
\hline 22 & Commercial area \\
\hline 27 & Mixed area(office, commercial and university) \\
\hline 29 & Mixed area(office, commercial and university) \\
\hline 31 & University \\
\hline 34 & Residential area \\
\hline
\end{tabular}

Source: own elaboration

The distribution of Weibo sub-centers of the weekend is not located at the very center of Beijing city (Figure 13), many of them are out of the second ring road and concentrated in the northern part of Beijing. The figure also overlaps the potential sub-centers of the other three periods for comparison. The overlap between weekend sub-centers and other potential areas are only two of them: the number 1 is located in Chaoyang district and the number 27 are in the Haidian district. However, most of the potential sub-centers in different periods are quite close to each other. There are seven places overlap in three different periods: the airport, universities, Dongdan commercial area, and Tian'anmen Square and Guomao CBD. All types of these land use could maintain a higher intensity of human activities.

Figure 13. Confirmed sub-centers at the weekend and overlapping potential areas

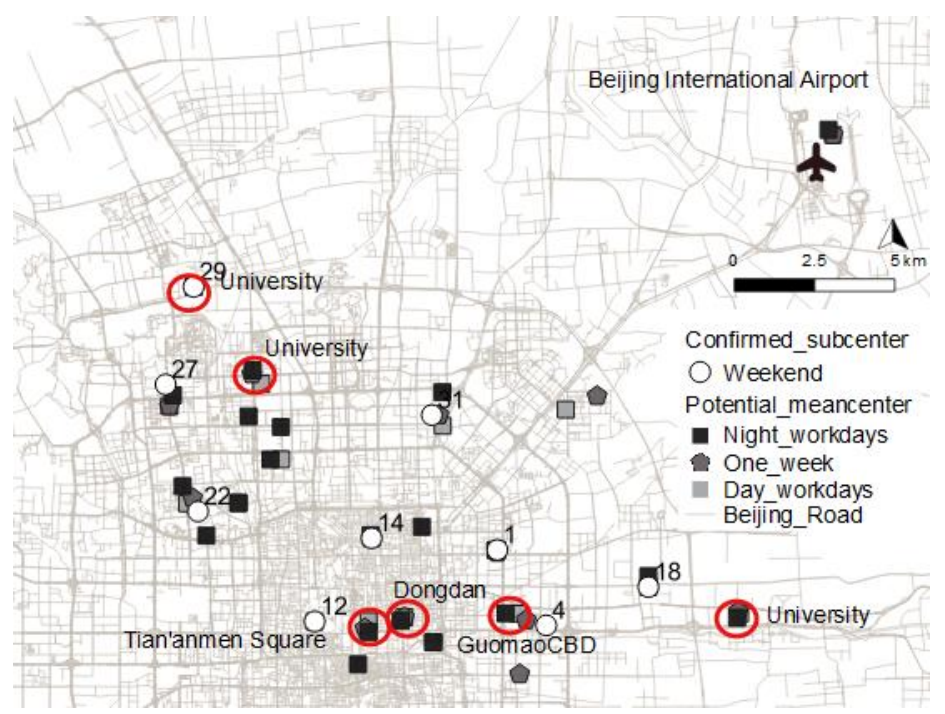

Source: own elaboration

ACE, 15 (4.3) CC BY-ND 3.0 ES | UPC Barcelona, Spain |Analysis of the Spatial Structure of Beijing from the point view of 


\section{Discussion and conclusion}

In summary, the urban structure of Beijing is indeed polycentric, though the high-density clusters mainly gathered within the fifth ring road of Beijing. Statistically, according to the result of the model, the period of weekend is the only one which presents the polycentric structure: there are sub-centers which Weibo-density is above to what is predicted by the distance of them from the Weibo-CBD. However, the poor performance of the negative exponential model also indicates that the Weibo density only has a weak correlation with the distance to the center. Moreover, as the Local Moran I's results show, the Weibo activities actually varies from place to place within the central area. Those Weibo sub-centers can present the major urban active areas, such as Zhongguancun, the traditional city center and the airport, etc. Last but not the least, it is necessary to stress that Weibo sub-centers are not employment centers. The employment center only considers the working activities rather than other human activities, such as recreational activities or tourist activities. The failure of the model may indicate that the empirical analysis of urban spatial structure requires more than pure employment analysis.

All Weibo sub-centers of the weekend and those potential areas of other periods are located in the northern part of Beijing. It is probably caused by the development of the educational zone since the 1950s and the falling of the first industries in the southern area due to the change in planning restrictions produced by the air pollution evident since the 1970s. Accordingly, the lack of Weibo subcenter in the southern part of Beijing is associated with the economic structural reform, because many heavy industry factories were located in that area.

Secondly, Weibo data is proved to be a useful data source to study the urban structure and urban functional areas. Those confirmed Weibo sub-centers actually belong to regions where are vivid zones, such as commercial areas and places of interest. Compared with the employment data, Weibo data can reflect the various types of land use more directly. Moreover, the employment data exclude the possibility that zones of universities could be potential sub-centers. Because most of the undergraduates and graduates live in the dormitories of universities in China, it forms another type of center of human activities.

Thirdly, the Weibo potential sub-centers imply the difference of human activities in different periods. It can be observed the difference in active Weibo areas between workdays and the weekend. For example, Zhongguancun as a major employment center of Beijing has more active grids during workdays than at the weekend. Meanwhile, it is reasonable to infer that working people post fewer Weibos in working places during workdays, and thus tourist attractions display a higher degree of activities in workdays by contrast. Conversely, people tend to go to recreational places or stay at home at the weekend, hence, commercial and residential areas are more active in the weekend.

Nevertheless, Weibo data exhibit limitations when it is applied to study the urban structure. Firstly, it cannot identify land uses without using exogenous data. The distribution of Weibo density is not enough to describe the whole situation of the city. It relies on other data that can provide the details of the land-use and social-economic information of a specific area. Secondly, the bias that is caused by types of users and users' preferences could affect the representativeness of Weibo data. For example, the major users of Weibo are aged from 18 to 35 years-old who tend to stay in other places longer than in their homes, thus the distribution of Weibo could not reflect residential areas very precisely. 


\section{Acknowledgment}

This paper is an evolution of the author's master thesis - The Analysis of the Spatial Structure of Beijing from The Point View of Weibo Data. It is also related to the research group of CPSV, under the reference MINECO CSO2012-33441.

\section{Authorship}

The first author has been in charge of data collection, analysis and writing paper, and the second author has made the guidance and revision of the paper

Conflict of interests: Authors declare no conflict of interest.

\section{Bibliography}

Ai, W.; Zhuang, D., \& Liu, Z. (2008). The Variation of Urban Land Use in Beijing in the Last One Hundred Year. Geoinformatics, 10(4), 489-494.

Beijing Haidian District Statistical Yearbook 2015. National Bureau of Statistics of China Beijing Census 2015.

Chi, G.; Liu, Y.; Wu, Z., \& Wu, H. (2015). Ghost cities analysis based on positioning data in China. arXiv preprint arXiv:1510.08505.

Cranshaw, J.; Schwartz, R.; Hong, J.; \& Sadeh, N. (2012, May). The livehoods project: Utilizing social media to understand the dynamics of a city. In Sixth International AAAl Conference on Weblogs and Social Media.

De Ureña, J. M.; Pillet, F., \& Marmolejo, C. (2013). Aglomeraciones/regiones urbanas basadas en varios centros: el policentrismo. Ciudad y Territorio Estudios Territoriales (CYTET), 45(176), 249-266. Retrieved from: https://recyt.fecyt.es/index.php/CyTET/article/view/76200

Ding, C., \& Zhao, X. (2014). Land market, land development and urban spatial structure in Beijing. Land Use Policy, 40, 83-90.

Feng, J., \& Zhou, Y. (2003). The social spatial structure of Beijing Metropolitan Area and its evolution: 1982-2000. Geographical Research, 22(4), 465-483. DOI: https://doi.org/10.1504/IJSSS.2014.059923

Ferreira, N.; Poco, J.; Vo, H. T.; Freire, J., \& Silva, C. T. (2013). Visual exploration of big spatio-temporal urban data: A study of New York city taxi trips. IEEE transactions on visualization and computer graphics, 19(12), 2149-2158. https://doi.org/10.1109/TVCG.2013.226

Garcia-López, M. À., \& Muñiz, I. (2010). Employment Decentralisation: Polycentricity or Scatteration? The Case of Barcelona. Urban Studies, 47(14), 3035-3056. Retrieved from https://www.jstor.org/stable/43081545

Giuliano, G., \& Small, K. A. (1991). Subcenters in the Los Angeles region. Regional Science and Urban Economics, 21,163-182. DOI: https://doi.org/10.1016/0166-0462(91)90032-1

Green, N. (2007). Functional polycentricity: A formal definition in terms of social network analysis. Urban Studies, 44(11), 2077-2103. DOI: https://doi.org/10.1080/00420980701518941 
Hägcrstrand, T. (1970). What about people in regional science? In Papers of the Regional Science Association (Vol. 24). DOI: https://doi.org/10.1007/BF01936872

Huang, D.; Liu, Z., \& Zhao, X. (2015). Monocentric or polycentric? The urban spatial structure of employment in Beijing. Sustainability, 7(9), 11632-11656. DOI: https://doi.org/10.3390/su70911632

Jiang, S.; Ferreira Jr, J., \& Gonzalez, M. C. (2012, August). Discovering urban spatial-temporal structure from human activity patterns. In Proceedings of the ACM SIGKDD international workshop on urban computing (pp. 95-102). Retrieved from https://www.cs.uic.edu/ urbcomp2012/papers/UrbComp2012 Paper27 Jiang.pdf

Jiang, S.; Ferreira, J., \& González, M. C. (2012). Clustering daily patterns of human activities in the city. Data Mining and Knowledge Discovery, 25(3), 478-510. DOI: https://doi.org/10.1007/s10618-012-0264-z

Kuang, W. (2012). Spatio-temporal patterns of intra-urban land use change in Beijing, China between 1984 and 2008. Chinese Geographical Science, 22(2), 210-220. DOI: https://doi.org/10.1007/s11769-012$\underline{0529-x}$

Liu, Y.; Wang, F.; Xiao, Y.; \& Gao, S. (2012). Urban land uses and traffic 'source-sink areas': Evidence from GPS-enabled taxi data in Shanghai. Landscape and Urban Planning, 106(1), 73-87. DOI: https://doi.org/10.1016/j.landurbplan.2012.02.012

Long, Y., \& Thill, J. C. (2015). Combining smart card data and household travel survey to analyze jobshousing relationships in Beijing. Computers, Environment and Urban Systems, 53, 19-35. DOI: https://doi.org/10.1016/j.compenvurbsys.2015.02.005

Marmolejo-Duarte, C., \& Cerda-Troncoso, J. (2012). La densidad-tiempo: otra perspectiva de análisis de la estructura metropolitana. Scripta Nova, 16. Retrieved from http://www.ub.edu/geocrit/sn/sn402.htm

Marmolejo-Duarte, C., \& Cerda-Troncoso, J. (2020). Metropolitan Barcelona 2001-06, or how people's spatial-temporal behaviour shapes urban structures. Regional Studies, 54(4), 563-575. DOI: https://doi.org/10.1080/00343404.2019.1583326

Marmolejo-Duarte, C.; Aguirre-Núñez, C., \& Roca -Cladera, J. (2013). Revisión de la densidad de empleo como medio para detectar sub-centros metropolitanos: un análisis para Barcelona y Madrid. ACE: Architecture, City and Environment, 8(23), 33-64. DOI: http://dx.doi.org/10.5821/ace.8.23.2596

Marmolejo-Duarte, C. R.; Echavarria-Ochoa, J. C., \& Biere-Arenas, R. M. (2016). El valor de la centralidad: Un análisis para la Barcelona metropolitana. ACE: Architecture, city and Environment, 11(32), 95-112. DOI: http://dx.doi.org/10.5821/ace.11.32.4834

McDonald, J. F. (1987). The identification of urban employment subcenters. Journal of Urban Economics, 21(2), 242-258. DOI: https://doi.org/10.1016/0094-1190(87)90017-9

McDonald, J. F.; \& Prather, P. J. (1994). Suburban employment centres: The case of Chicago. Urban studies, 31(2), 201-218. Retrieved from https://www.jstor.org/stable/43196088

McMillen, D. P., \& Lester, T. W. (2003). Evolving subcenters: employment and population densities in Chicago, 1970-2020. Journal of Housing Economics, 12(1), 60-81. DOI: https://doi.org/10.1016/S1051$1377(03) 00005-6$

Min, H.; Fengjun, J., \& Fath, B. D. (2010). Measurement and spatial distribution of urban land use compactness in Chaoyang District of Beijing, China. Chinese Journal of Population Resources and Environment, 8(4), 3-9. DOI: https://doi.org/10.1080/10042857.2010.10684997

ACE, 15 (4.3) CC BY-ND 3.0 ES | UPC Barcelona, Spain |Analysis of the Spatial Structure of Beijing from the point view of 23 Weibo Data. DOI: http://dx.doi.org/10.5821/ace.15.43.9302 
Pred, A. (1984). Place as historically contingent process: Structuration and the time-geography of becoming places. Annals of the association of American geographers, 74(2), 279-297. Retrieved from https://www.jstor.org/stable/2569284

Qi, G.; Li, X.; Li, S.; Pan, G.; Wang, Z., \& Zhang, D. (2011, March). Measuring social functions of city regions from large-scale taxi behaviors. In 2011 IEEE International Conference on Pervasive Computing and Communications Workshops (PERCOM Workshops), (pp. 384-388). IEEE. DOI: https://doi.org/10.1109/PERCOMW.2011.5766912

Roca Cladera, J.; Marmolejo Duarte, C.R., \& Moix, M. (2009). Urban structure and polycentrism: Towards a redefinition of the sub-centre concept. Urban Studies, 46(13), 2841-2868. DOI: https://doi.org/10.1177/0042098009346329

Shen, Y.; Kwan, M. P., \& Chai, Y. (2013). Investigating commuting flexibility with GPS data and 3D geovisualization: a case study of Beijing, China. Journal of Transport Geography, 32, 1-11. DOI: https://doi.org/10.1016/j.jtrangeo.2013.07.007

Stephens, M., \& Poorthuis, A. (2015). Follow thy neighbor: Connecting the social and the spatial networks on Twitter. Computers, Environment and Urban Systems, 53, 87-95. DOI: https://doi.org/10.1016/j.compenvurbsys.2014.07.002

Thrift, N. (1977, January). An introduction to time-geography. Geo Abstracts, University of East Anglia.

Wang, Y.; Wang, T.; Tsou, M.H.; Li, H.; Jiang, W., \& Guo, F. (2016). Mapping dynamic urban land use patterns with crowdsourced geo-tagged social media (Sina-Weibo) and commercial points of interest collections in Beijing, China. Sustainability, 8(11), 1202. DOI: https://doi.org/10.3390/su8111202

Wong, D.W.S., \& Lee, J. (2005). Statistical analysis of geographic information with ArcView GIS and ArcGIS (No. G 70.212. L43 2005). Hoboken, NJ: John Wiley \& Sons.

Wu, Q.; Li, H.Q.; Wang, R.S.; Paulussen, J.; He, Y.; Wang, M.; ... \& Wang, Z. (2006). Monitoring and predicting land use change in Beijing using remote sensing and GIS. Landscape and urban planning, 78(4), 322-333. DOI: https://doi.org/10.1016/j.landurbplan.2005.10.002

Xie, Y.; Fang, C.; Lin, G.; Gong, H., \& Qiao, B. (2007). Tempo-spatial patterns of land use changes and urban development in globalizing China: a study of Beijing. Sensors, 7(11), 2881-2906. DOI: https://doi.org/10.3390/S7112881

Yang, L., \& Marmolejo-Duarte, C. (2019). Identifying tourist-functional relations of urban places through Foursquare from Barcelona. GeoJournal, 1-18. DOI: https://doi.org/10.1007/s10708-019-10055-9

Yuan, J., Zheng, Y., \& Xie, X. (2012, August). Discovering regions of different functions in a city using human mobility and POIs. In Proceedings of the 18th ACM SIGKDD international conference on Knowledge discovery and data mining (pp. 186-194).

Zhi, Y., Liu, Y., Wang, S., Deng, M., Gao, J., \& Li, H. (2014). Urban spatial-temporal activity structures: A new approach to inferring the intra-urban functional regions via social media check-in data. arXiv preprint arXiv:1412.7253.

Zhong, C., Batty, M., Manley, E., Wang, J., Wang, Z., Chen, F., \& Schmitt, G. (2016). Variability in regularity: Mining temporal mobility patterns in London, Singapore and Beijing using smart-card data. PloS one, 11(2), e0149222.

ACE, 15 (4.3) CC BY-ND 3.0 ES | UPC Barcelona, Spain |Analysis of the Spatial Structure of Beijing from the point view of 24 Weibo Data. DOI: http://dx.doi.org/10.5821/ace.15.43.9302 